\title{
A Study of Beam Sensitive Materials Using High resolution, ULV Scanning Electron Microscopy
}

Mine Nakagawa*, Shuichi Takeuchi*, Atsushi Muto*, Takeshi Ogashiwa*, Sara White***, and Mitsugu Sato **

*Hitachi Science Systems, Ltd., 11-1, Ishikawa cho, Hitachinaka, 312-0057 Japan

**Hitachi High-Technologies Corp., 882 Ichige, Hitachinaka, Ibaraki, 312-8504 Japan

***Hitachi High-Technologies America Inc., 944 Clopper Road, Gaithersburg, MD 20878-1301, USA

Low voltage scanning electron microscopy has become common both for topmost surface imaging and reducing beam damage [1]. Lately, high resolution, ultra-low-voltage (ULV) imaging (less than $500 \mathrm{~V}$ ) has been realized by beam retarding [2] and/or boosting [3] techniques. In this study, some beam sensitive materials are observed by the Hitachi S-4800, which employs a cold field emission source, snorkel type objective lens and a retarding function [4].

Figure 1 shows images of PTFE (polytetrafluoroethylene). Images were captured first at 50kX (high magnification) and then at a lower magnification- $20 \mathrm{kX}$, at the same area in order to identify morphological changes between $100 \mathrm{~V}$ and $500 \mathrm{~V}$. The $500 \mathrm{~V}, 50 \mathrm{kX}$ image (Fig.1(a)) exhibits a different surface structure when compared to the surrounding area seen at $20 \mathrm{kX}$ (Fig.1(b)). On the other hand, with the $100 \mathrm{~V}$ landing voltage, the $50 \mathrm{kX}$ image (Fig.1(c)) has almost the same topographic information as the 20kX image (Fig.1(d)), even though EB dose at $50 \mathrm{kX}$ is 6 times more than that at $20 \mathrm{kX}$. This shows that $100 \mathrm{~V}$ imaging minimizes morphological change for this specimen, which may exhibit crystalline transformation between 50 to 60 degrees $\mathrm{C}$.

Figure 2 shows images of ArF resist at $100 \mathrm{~V}$ and $800 \mathrm{~V}$. ArF resist shrinks because of solvent evaporation due to chemical reaction or temperature rise by EB irradiation [5]. The $100 \mathrm{~V}$ image (Fig.2(b)) can evaluate edge roughness more accurately than $800 \mathrm{~V}$ (Fig.2(a)) with less shrinkage.

Additional studies are reported such as the combinations of coating or cryogenic techniques, and ULV imaging for a wider field of applications.

[1] M. Osumi, et al. Proc. of $46^{\text {th }}$ Electron Microscopic Society of America, 208-211 (1998)

[2] P. F. W. Peace, IEEE $9^{\text {th }}$ Electron, Ion and Laser Beam Technology, 176-187 (1967)

[3] J. Frosien, et al., J. Vac. Sci. Technol B7 1874 (1989)

[4] A. Muto, et al. Proc. Microscopy and Microanalysis 9, Suppl.2, 146-147 (2003)

[5] T. Kudo, et al. J. Photopolymer Sci. Technol. 14, no. 3, 407-417 (2001) 

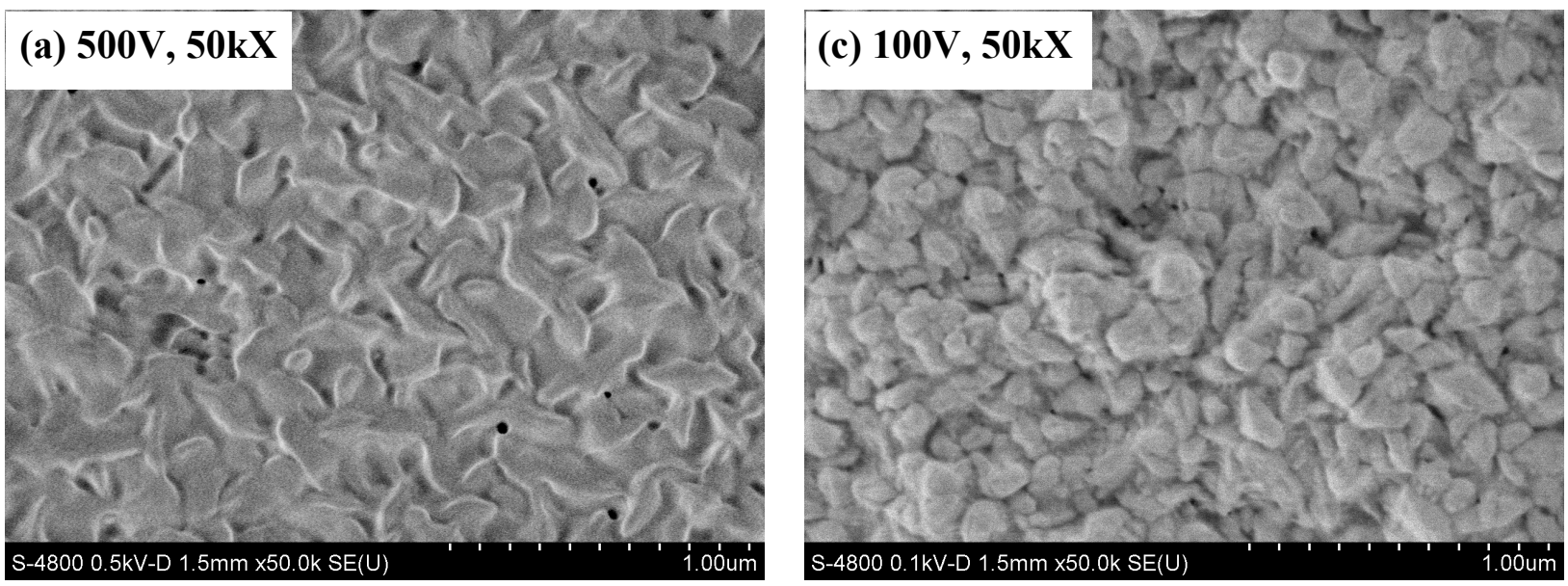

\section{(b) $500 \mathrm{~V}, 20 \mathrm{kX}$}
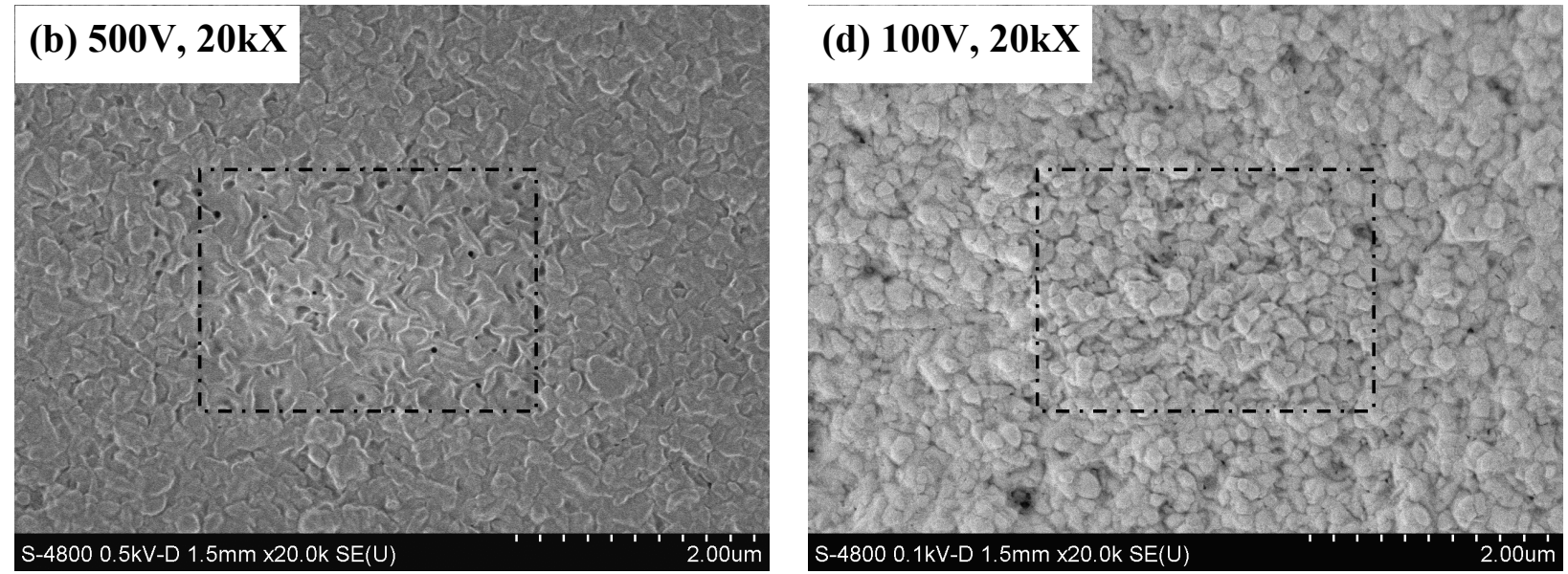

Figure 1 PTFE images
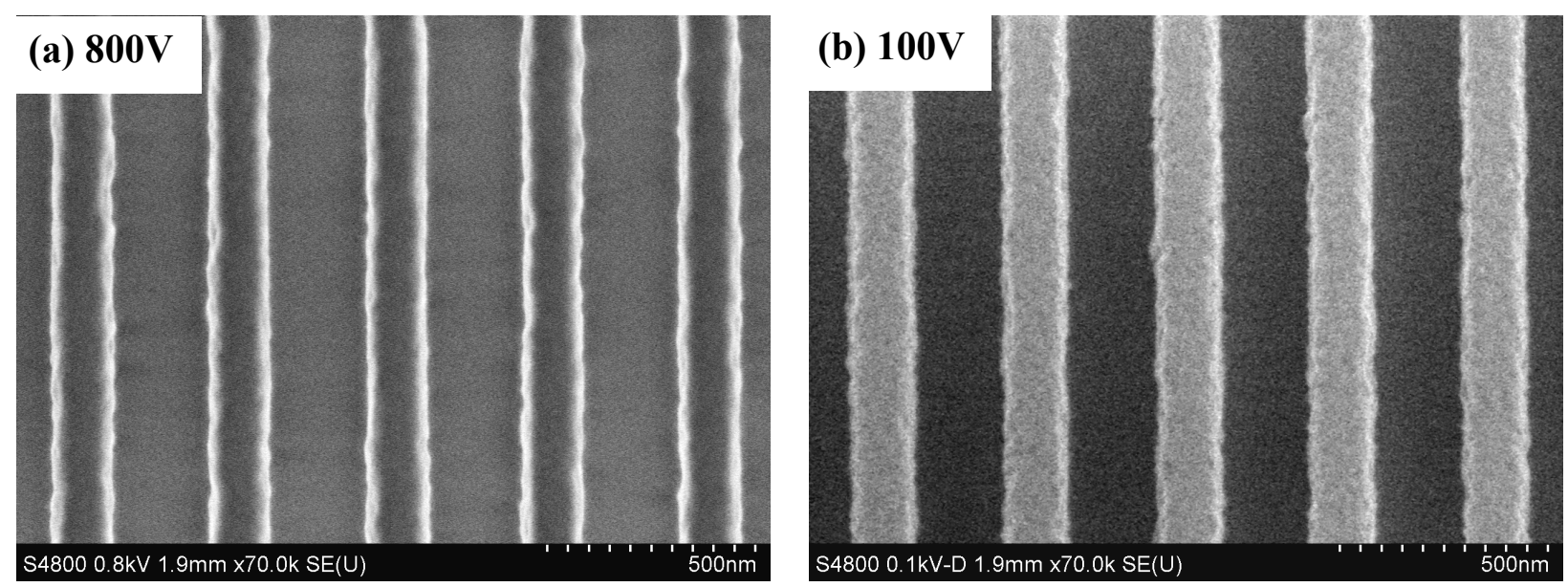

Figure 2 ArF resist images 